\title{
Educational podcasts: A genre analysis
}

\begin{abstract}
Academic attention to educational podcasts has grown significantly in recent years. However, to date the concept of genres in podcasting is yet to gain scholarly attention. By examining genres emergent from a corpus of educational podcasts available online this paper introduces the value of genre analysis to educational podcast research. It proposes three genres, named 'The Quick Burst', 'The Narrative', and 'The Chat Show'. The three genres show both the versatility of podcasting for education and how genre analysis could introduce new ideas to the educational podcasting literature, including ideas about supporting deep learning in e-learning environments.
\end{abstract}

Keywords: podcasts; genre analysis; educational media

Podcasting has enjoyed growing interest in education studies literature over the past decade. Of the studies that have emerged in relation to instructor-created podcast use in education, there has been an almost exclusive focus on action research into podcasts from within education institutions (Hew, 2009; Fernandez, Sallan \& Simo, 2015; Drew, 2017). To date, there is no literature that examines emergent genre conventions in educational podcasts, nor sustained scholarly attention to the ways educational podcasts 
produced by entrepreneurs of the medium act as 'cognitive tools' (Kim \& Reeves, 2007, p 207) that work with students to enhance their learning experience. The entrepreneurial educational podcasts that are widely available and consumed on the web, however, can provide significant insights into the ways the affordances of the medium can be used by instructors to produce diverse and educationally beneficial texts. It is therefore the aim of this paper to explore genre forms identifiable from entrepreneurial educational podcasts, and examine some pedagogical lessons that they offer for instructors' podcast design practices.

Genre analysis has several implications for education podcasting scholarship and practice. Firstly, it provides frames of reference for exploring ways of teaching and learning that are possible with and through new media (Bakardjieva, 2006).

Furthermore, it can also reveal podcasting's textual formations that are to date underexamined and understated within the literature (Lüders, Prøitz \& Rasmussen, 2010). Thirdly, genre analysis can help practitioners 'determine the choice of genre to suit a particular context', and utilise, modify and subvert 'generic conventions' in the creation of new texts (Bhatia, 1997, p. 361). Indeed, creativity in the modification and subversion of textual conventions is a key feature of Web 2.0 media that teachers and students can and do take advantage of regularly to create and disseminate knowledge in unique and informative ways (see, for example, Jenkins, 2006). 
The paper begins with a discussion of the unique affordances of podcasting, before examining how teacher-produced podcasts have been explored in education studies literature to date. The paper then turns to a discussion of the genre analysis methods used in this study, and uses those methods to introduce three genres for education podcasting. The three genres introduced provide insights into how educational podcasts can work as 'cognitive tools' inasmuch as they not only liven up e-learning spaces, but also have 'capabilities to complement a learner's cognition' (Kim \& Reeves, 2007, p. 217 ) in ways that enable and support deep learning online.

\section{Podcasting's affordances}

Podcasting began its development in the early 2000s, with the term 'podcast' coined in February 2004 by Ben Hammersley in an article for The Guardian (Bonini, 2015). A podcast is a digital packet of audio which is generally part of a series, released at regular intervals and automatically downloaded to personal media devices when made available through Really Simple Syndication (RSS) feeds. Although primarily designed for RSS feed downloads, they are also widely available for manual download online. Since 2004, podcast aggregation sites like Juice, Spotify and iTunes have been the primary way in which podcasts have been hosted and distributed globally, providing consumption via both RSS and manual download means. 
In recent years, entire academic articles have been dedicated to examining the qualities of podcasting that differentiate it from related media such as radio and audiobooks (Bonini, 2015; Berry, 2016). Notably, online distribution means that podcasters can bypass editing requirements of publishing houses, radio's costly distribution infrastructure, censorship and interference by state powers, as well as programming constraints such as the need to fit into a broadcast timeslot. The lack of such constraints means podcast content is often seen as authentic, particularly in contrast to its cumbersome and highly regulated radio cousin (Meserko, 2015).

However, what creates 'podcastness' (Berry, 2016, p. 11) is not merely the distribution qualities outlined above, but also a set of production and consumption practices (Berry, 2016). Podcasting enables consumers to have the power over how and when to consume content. Such power includes the ability to play, pause and rewind a podcast at will through personal devices. This makes podcasting more often listened to via the intimacy of headphones, and from beginning to end rather via tuning-in and out of radio airwaves. As Berry (2016) has argued, it is therefore more commonly an active listener that comes to podcasting with the explicit intent of listening to a program from beginning to end, rather than a listener of convenience who might use radio as background noise or a time filler. These features are of particular benefit when podcasts are applied to education, particularly at a time when distance and online learning are 
becoming increasingly popular and students are requesting 'on-demand' learning experiences that can take place anytime, anywhere.

The special production and consumption aspects of podcasting have opened up 'a new and interesting space for media and cultural interaction' (Wrather, 2016, p. 44; Berry, 2016). With a unique constellation of affordances and cultural practices, podcasting it has attracted a vast spectrum of producers and consumers engaging with unique genretexts. It has steadily grown in popularity since 2004 , and while exceptionally popular amongst independent producers, it has also been co-opted by traditional broadcast companies like $B B C$ and The Guardian and boutique podcasting companies such as Radiolingua. It has furthermore been particularly well taken up by comedians, religious evangelists, and increasingly, educators. It is to the latter that this paper now turns.

\section{Podcasting for education}

Podcasting for education has been prolific in recent years, both inside and outside of educational institutions. A growing number of higher education institutions around the world have incorporated podcasts into both on-campus e-learning modules (Hew, 2009). Despite the growth of podcasting in educational institutions, however, there is little empirical evidence of its tangible effects for improving student grades (Abdous, Facer \& Yen, 2012; Abt \& Barry, 2007; Kemp et al., 2010; Lazzari and Betella, 2007). Nonetheless, podcasts are widely seen as positive learning tools that can have the 
tangible benefit of bringing teachers and learners together, often across long distances. Rather than being framed as tools for enhancing student grades, then, podcasts are widely seen as a means for engaging students in ways that might motivate them in learning content and increasing rapport between teacher and students (Edirisingha, Hawkridge \& Fothergill, 2010; Carle, Jaffe \& Miller, 2009; Fernandez, Simo \& Sullan, 2009).

Despite the optimism about podcasts' potential for engaging and motivating students there has been a degree of pushback from scholars concerned that the availability of podcasts might deter students from engaging with weekly readings or, for blended mode students, attending in-class sessions (Larkin, 2010; Campbell, 2005; Fernandez, 2007). This has led to a great deal of trepidation about releasing podcasts for students to listen to, and a general perception of podcasting as only valuable as a peripheral learning tool whose value is not in teaching new content or engaging students in deep learning, but rather to support the 'real' learning that takes place elsewhere (Hew, 2009; Fernandez, Simo and Sallan, 2009; McGarr, 2009). I have argued previously (Drew, 2017) that a vision of podcasting as supplementary to real learning tends to detract scholars form considering ways podcasts might act as 'cognitive tools' (Kim \& Reeves, 2007) in their own right which might be used to assist students to more deeply engage with learning content. 
Another way forward in the study of the potentialities of podcasting in education, which I believe is valuable for broadening the scope of the above literature and focusing attention on podcasts as cognitive tools for learning, is to look at trends in the types of podcast that already exist — or what we might call 'genres'. Through genre analysis we can build an appreciation of the general, recurrent, and recognisable structures of podcasts, and develop 'frames of reference' (Lüders, Prøitz \& Rasmussen, 2010, p. 947) for thinking about the sorts of podcasts practitioners can envisage using in their own educational contexts.

\section{Genre analysis}

Genre analysis is widely used to examine how media convey information in ways that are engaging and intelligible for the target audience. John Swales (Swales, 1990; Tardy \& Swales, 2014), a central figure in genre analysis methodologies, explains genres as that have common communicative purpose and form. However, genres are commonly understood as not 'static' but fluid, always changing and evolving with practice. The fluidity of genre formations is particularly relevant to new media genres, whose conventions have been exposed to significant experimentation and contestation as a result of their ease of production by everyday internet prosumers (Guinda 2015; Bakardjieva, 2006). This phenomenon is often described as 'convergence culture' (Jenkins, 2006), whereby longstanding genre forms from more traditional media meet 
the new affordances of the internet, and the lines between producer and consumer are blurred, opening up new intertextual and interactive possibilities for genre production. A common method for the analysis of genres is the 'move-step' approach proposed by Swales (1990; Tardy \& Swales, 2014). The concern for 'moves' in genre analysis is seen as a means for describing 'the functions of particular portions of texts in relation to the overall task' (Briones, 2012, p. 59). In practice, this is often achieved via a threelevel analysis of a genre. On the first level, an explanation of the genre's communicative purpose is required, which is the common overall use of the genre. The second level is the move structures that characterise the genre, which are conventionalised textual functions that recur across genre-texts. Move structures are often identifiable via the third level, which is analysis of the rhetorical steps taken in the realization of the move. As an example, while a move in the 'recipe' genre might be to provide a chronological list of actions, common rhetorical steps for the realization may be the use of phrases such as 'stir thoroughly' that conventionalise how the list might be actualised.

For the genre analysis in this study, a corpus of educational podcasts was gleaned from the most downloaded podcasts in the 'Education' categories of popular podcast aggregation websites including iTunes, podbay and podcastalley—sites selected for being mainstream aggregation sites rather than ones that are tied to university-linked podcasts. Only podcasts that commonly appeared across the three sites were selected, leaving a final corpus of 35 podcast series for examination. Given the sheer number of 
podcasts in each series, eight episodes of each series were included in analysis, including the first three episodes released, as well as five other randomly selected episodes.

During the first pass of textual analysis, notes were taken on the overarching ‘communicative purposes' (Tardy \& Swales, 2014) of each podcast, and tentative genres were noted based on the podcasts' raison d'etre. During the second pass, podcast design (Carvalho et al, 2009; Drew, 2017) and editing (Fernandez, Sallan \& Simo, 2015) factors including type of content (new materials, assessment discussion, guidelines for practice), length (short 1-5 minutes; medium 5-15 minutes; long 15+ minutes), author (teacher, student or other), style (formal or informal), purpose (inform, reflect, motivate, etc), mode of address and sound effects, were observed in order to identify potential 'moves' and 'steps' common across podcasts with similar communicative purposes. Following the second pass, three broad genres had coagulated. In the following paragraphs, these genres are introduced, with some key moves and steps briefly outlined.

\section{The Quick Burst}

Communicative Purpose. 'The Quick Burst' describes a form of podcast whose communicative purpose is the succinct delivery of one key piece of information. Commonly below 5 minutes in length, and very often described as a 'one minute' 
podcast, texts in this genre present singular learning tips or key ideas to listeners. This genre has been identified across multiple learning areas, including science, language learning, history, and general interest ('Grammar Girl's Quick and Dirty Tips', 'History in Five Minutes', ‘2-Minute English', ‘60 Second Science', 'Two Minute Takeaway’).

Move 1: Controlled, Short Timeframe. Texts that conform to this genre of podcast are generally very conscious of self-imposed time limits. While it has been noted earlier in this piece that podcasting has the affordance of not needing to fit into a set broadcast timeframe, it appears this genre of text takes its cue from a marketplace of consumers desiring a fast fact that requires minimal time commitment. As the slogan for the 'One Minute Tip' podcast exemplifies, The Quick Burst is a genre that caters 'for busy people' (Chambers, 2011). Learner demand for podcast brevity has also previously been noted in many studies on educational podcasting, which report through student surveys that the interest and focus of learners can rapidly wane after the first five minutes (Lee \& Tynan, 2008; Kidd, 2011), justifying brevity in podcasting.

The consciousness of time constraints is evidenced in the key step of referring to brevity in the podcast title ('One Minute Norwegian', 'Quick and Dirty Tips'). A second common step within this move, which is also designed to achieve the controlled timeframe, is the use of a stopwatch sound effect (such as in 'One Minute Tip', 'One Minute French', and 'One Minute Norwegian') to signify the beginning of the podcast's learning timeframe. Such a move is reminiscent of the time-controlled contexts of 
standardised tests or 'pop quizzes' in classroom contexts. The pressure imposed by time constraints works to push learners in the direction of rote and repetitive learning, delivering content not through considered thought but quick-fire response at the introduction of a stimulus. This genre might therefore be seen as a behaviourist tool for learning targeted at lower-order cognitive tasks such as fact recall. As a cognitive tool, the Quick Burst podcast might work to assist learners in their reflection upon previous content learned; however deeper learning and problem solving capacities are unlikely in the pressurised environment of a one to five minute podcast. The 'Quick Burst' genre may therefore be met with caution, but possibly also used wisely in contexts designed for warm-ups, summaries or student re-engagement.

Move 2: Buoyancy. With brevity comes the requirement to instantly catch attention, commonly achieved in this genre through buoyancy in tone of address ('One Minute Tip', '60 Second Science'). Steps to achieve this move can include crisp and fast-paced speech, optimism in a presenter's voice, and minimal pauses in speech. The mode of address tends to be direct and curt to achieve maximum information in minimum time. Podcasts like 'Science Underground' might also play a soft rolling tune in the background throughout, giving additional sense of progression-much like in a radio news update. In this sense, the tone of address in the texts in this genre is more akin to a television advertisement or breaking news segment, than the contemplative mood set in the Narrative and Chat Show genres discussed later in this piece. 
With many practitioners concerned with losing students' attention, it may make sense to use this genre to produce a clean, buoyant message to students to draw them into a learning experience and enliven online learning. Furthermore, the brevity of the podcasts allows for regularity of publication, as exemplified by texts such as 'Daily French Podcast' which provide new content every 24 hours. However, higher-order skills like analysis and evaluation are notably absent in 'Quick Burst' podcasts, which do not have the timeframe to delve into depth on the key ideas being presented, severely limiting the potential of such a podcast to move beyond supplemental provision of information towards a theoretical orientation that sees podcasting as a central learning tool for encouraging deep or sustained learning of course content.

\section{The Narrative}

Communicative Purpose. 'The Narrative' has the communicative purpose of telling a story about a topic. The use of narrative in history podcasting has elsewhere been described as 'a combination of broadcast radio's episodic format, its sense of “'liveness,', ... juxtaposed with the long format and narrative voice of print or audio books' (Salvati, 2015, p. 233). The Narrative's mix of radio and audio book tones thus reveal the ways the genre has grown out of extant genres from other media, but developed its own unique style. This genre is very common among history podcasts whereby continuous narratives can run for several hundred episodes in a row ('Hardcore History', 'British History Podcast', 'The History Chicks', 'Revolutions'). 
Move 1: Storytelling. The first and main move that characterises this podcast is storytelling. A story functions as the central feature of these genre-texts, taking up the majority of the $40-80$ minute packets of audio. Standing in stark contrast to The Chat Show genre discussed later in this piece, The Narrative involves sustained storytelling directly from storyteller to listener with minimal breaks in narrative for free-form discussion. This results in less emphasis on knowledge consolidation, and a requirement of listeners for patient attention to the storyline. Fortunately, with the affordance of pause, rewind and storage, such podcasts can be re-watched either in their entirety or in segments in order to assist students to take notes and listen again before exams. In this sense, the podcasts assist learners in engaging with lessons in their own time and at their own pace in order to consolidate learning and be confident with lesson content before moving on.

Storytelling is an exceptionally longstanding pedagogical style —indeed, this pedagogical approach remains dominant in some of the world's longest living oral cultures (Egan, 2001). The key rhetorical steps to achieve storytelling in this genre at times adapt the rhetorical steps of soliloquy in theatre, including voice articulation such as rushed and breathless speech during climatic moments of the stories and strategic pauses. These verbal strategies are complemented by digital enhancement affordances of the podcast medium, like the drums of war as battle approaches (British History Podcast, Episode 14) and regular leitmotif soundtracks leading into and out of story 
segments. In this sense, the stories in 'The Narrative' genre do more than present new information to the listener or even to merely 'entertain' its audience; the genre's pedagogical importance is in the shaping of stories to teach though the affective power of sound. In the tradition of Barthes (1977), whose idea of the 'grain' of the voice appeals to the notion that voice contains a 'body' - a certain aesthetic appeal - many have highlighted how content is embedded in oral narratives in ways that are personal, affective, engrossing and memorable (Lindgren, 2016; Egan, 2001). Egan (2001, p. 3), for example, explains how the voice 're-sounds with a store of rhymes and rhythms' that make storytelling not only entertaining, but also a powerful means for supporting learning and committing in formation to memory (Drew, 2013; Egan 2001).

Move 2: Signposting and Cross-Linking. While storytelling makes up the central move, another characteristic feature of this genre is the use of signposting and cross-linking to support learning. Cross-linking involves weaving connections between podcasts within a series to develop cognitive links between lesson content across a unit or podcast series. This cross-linking strategy is evident in a wide range of new media texts that use the interconnectedness of the internet to add depth to the storytelling, perhaps most clearly through the use of hyperlinks on websites. Through cross-linking, podcasts can support students' meaning-making by verbally drawing otherwise disparate lesson content together to form a coherent narrative throughout the unit as a whole. 
Cross-linking is perhaps most telling in those moments when podcasters ask listeners to refer to their websites or supplementary materials for further information, such as in the case of 'The British History Podcast' which contains a 'learning materials' tab on its website; or 'Revolutions' which refers listeners to an extensive list of further sources online to continue knowledge building. Cross-linking is also common, however, at the beginning of a podcast's narrative, where the podcaster speaks to the audience about where the current podcast's story fits within the overarching narrative that the podcast series tells. It thus features as an important move for tying together the loose ends of narratives across podcasts in a series, and is reflective of the ways the individual texts within this genre generally work as integrated elements of a larger narrative.

Signposting and cross-linking, while perhaps evident in related media such as radio series or even live lectures, have unique possibilities in podcasts given that students can pause, rewind, or return to previous podcasts at will. These features can assist in developing rich learning environments that are consistent with the desires of e-learning designers to allow students to have a personal learning experience (Masden \& Potts, 2010) and learn at their own pace: to jump back and forth, pause for thought, jot down time markers to return to segments later, and so forth. In 'The Narrative' genre, then, the key moves of storytelling and signposting/cross-linking coalesce to create a unique genre form that supports engaging, emotive and self-directed e-learning.

\section{The Chat Show}


Communicative Purpose. 'The Chat Show' genre's communicative purpose is the utilisation of institutionalised conversation between two or more participants to explore various ideas and concepts. This definition of its purpose is borrowed from Ames' (2016) discussion of radio chat shows. Aimes explains chat shows as involving conversation that is institutionalised, inasmuch as it 'occurs for specific reasons, with each speaker occupying a specific position' (2016, p. 181) such as 'host' and 'guest'. While closely shadowing radio chat shows, podcast series in this genre tend to be more specific to topic areas than the general current affair tone of drive time radio (Ames, 2016). This may be because, as Wrather (2016) has argued, podcasting targets small but specific fan groups based on community interests rather than aiming for broadcast for the masses. The boutique nature of podcasting has, however, opened the space for chat shows that are specifically education-focused with topical relevance to a small but committed global listenership, particularly in the physical sciences ('The Skeptics Guide to the Universe', 'The Naked Scientists', 'Probably Science', 'Science Friday', 'Professor Blastoff'; 'Science for the People').

Move 1: Conversationalism. A key element of the 'Chat Show' genre, as opposed to the genres listed above, is engaged dialogue amongst panel members rather than predominantly single-host audio. Pedagogically, conversation between panels of multiple presenters engaged in institutionalised conversation has the potential to engage listeners in higher-order thinking skills like analysis and synthesis, unlike shorter Quick 
Burst podcasts. Take 'The Skeptics Guide to the Universe', which introduces a new key word in each podcast. The word is then used in conversation and the panel discusses its applicability to real-life contexts. The terms and ideas discussed are often debated amongst the panel who present a diversity of perspectives on the topic. This sustained conversation on key terms and ideas not only models critical thinking, but also the language conventions within scientific discourse communities (Aimes, 2016). These podcasts thus have the capacity to support learning by putting metalanguage into conversational context and model their form and function in everyday language situations. The language use in 'Chat Show' podcasts works to bridge the gap between the learning environment and the workplace, bringing the granular (Barthes, 1977) and authentic voices of experienced practitioners into the e-learning space to enliven and authenticate (Masden \& Potts, 2010) the learning experience.

Move 2: Wit. The importance of entertainment has been discussed in all three podcast genres proposed here, but 'The Chat Show' emerges as the genre most consciously targeted towards making audiences laugh. I lean towards the term 'wit' in describing this move to emphasize the blend of humour and intellectualism. Again following Ames, this genre takes from radio 'the ability for 'chat' to be a complex mix of both the comic and the serious' (2016, p. 182; Tolson, 1991). Indeed, the blurbs for several podcasts conforming to this genre introduce the hosts as both comedians and scientists ('Star Talk', 'Probably Science', 'The Infinite Monkey Cage Podcasts'). Take, as an 
archetypal example, Probably Science's tagline: 'Four professional comedians/incompetent scientists take you through this week in science', or public intellectual Neil deGrasse Tyson, who introduces the Season 7 Episode 24 podcast with 'I never do this alone and I've got my professional comedian co-host, Iliza Shlesinger'. This is perhaps a reflection of the extent to which both scientists and comedians have taken to podcasting as a way of progressing their craft and careers, much in the same way that many radio broadcasters emerge from standup comedy.

The 'Chat Show' genre's use of wit tends to function as a tool not only for entertainment, but also as a cognitive tool for student learning. Jokes become memorable and catchy anecdotes that humanise lesson content and place it into a story form. As Egan (2001, p. 3) articulates, placing learning content into storytelling form such as within a joke enables learners to 'seek out the affective meaning and the emotional resonance within the content' in order to enable learners to recall human stories rather than dry facts. This is all the more immersive given that the jokes in these podcasts are told through the voices of the presenters rather than written text, whereby the anecdote takes place at 'the encounter between language and a voice' (Barthes 1977, p. 181).

\section{Concluding discussion}


The three genres of educational podcasts examined in this paper have been used to exemplify the ways in which podcasting is a versatile tool to support and enhance student learning in e-learning environments. Short 'Quick Burst' podcasts, long-form 'Narrative' podcasts and conversational 'Chat Show' podcasts have each proven themselves to be popular educational texts for learners outside of formal institutions to learn and engage with communities of likeminded learners. The discussions above have shown how each genre has developed common 'moves' and 'steps' that are used in their design to cater learning experiences to particular audience requirements. However, these moves and steps also have consequences for how podcasts can be seen as cognitive tools (Kim \& Reeves, 2007) inasmuch as they assist learners in extending their knowledge. It has been argued here, for example, that the shorter 'Quick Burst' podcasts may be of some benefit for re-engagement of students through their buoyant approach, but their capacity to assist learners to engage at a deeper level of learning is questionable. Furthermore, much of the discussion about the 'Narrative' and 'Chat Show' genres has argued that the affective power of the 'voices' that podcasts bring to e-learning should not be understated, for voice is not only useful for 'enveloping the listener with the intimate expression of its character' (Masden \& Potts, 2010, p. 45), but also is a powerful means for supporting learning by embedding content in unique stories, antedotes and jokes of the storytellers involved. 
While in this paper three prominent genres have been examined for their capacity to both engage learners and work as cognitive tools to encourage deep learning, it is certainly possible that other genres can be identified in future studies. In particular, student-produced podcasts which were outside of the scope of this analysis might reveal some new insights into podcast design for education. Similarly, these genres might be of some benefit for assisting students in producing their own podcasts, whereby they might be able to learn from, modify or subvert existing genre styles in order to creatively produce and present knowledge — through group work using 'Chat Show' styles, individually by telling stories and developing 'Quick Burst' style presentations, or in inventive new ways.

Lastly, Lüders, Prøitz and Rasmussen's (2010, p. 928) argument that genre analysis 'uncovers hitherto insufficiently emphasized processes of communication' rings true when the findings of this genre analysis are compared to extant literature. It is evident that education studies has to an extent been boxed-in by institutionalised thinking in regards to the value of podcasting to education. It is the assumption in much of the literature on educational podcasting that podcasts should be supplemental texts in education courses (Hew \& Cheung, 2013; Drew, 2017), yet this is not corroborated here, whereby the podcasts here have commonly been the only or at least central tools for learning. 
Here, then, lies justification in genre analysis in educational podcasting. The paper opened by explaining that genre analysis is valuable for the examination of the possibilities of a medium, opening space for consideration of how genre conventions can be utilised, modified and subverted in the creation of new texts and for assisting learning (Tardy \& Swales, 2014). Feeding forward, this paper hopes to begin sustained conversation about genres in podcasting, but also to inform future thinking in regards to what is possible for podcasts for assisting learning both inside and outside of education institutions. 
Abdous M, Facer R and Yen C (2012) Academic effectiveness of podcasting: A comparative study of integrated versus supplemental use of podcasting in second language classes. Computers and Education 58: 43-52. DOI: 10.1016/j.compedu.2011.08.021.

Abt $\mathrm{G}$ and Barry $\mathrm{T}$ (2007) The quantitative effect of students using podcasts in a first year undergraduate exercise physiology module. Bioscience Education 10(1): 19.

Ames K (2016) Talk vs chat-based radio: A case for distinction. Radio Journal: International Studies in Broadcast \& Audio Media 14(2): 177-191.

Bakardjieva M (2006) Domestication running wild: From the moral economy of the household to the mores of a culture. In: Berker T, Hartmann M, Punie Y and Ward K (eds) Domestication of Media and Technology. Maidenhead: Open University Press, pp. 62-79.

Barthes, R. (1977). Image, music, text. New York: Hill and Wang.

Berry R (2016) Podcasting: Considering the evolution of the medium and its association with the word 'radio'. The Radio Journal International Studies in Broadcast and Audio Media 14(1): 7-22.

Bhatia VK (1997) The power and politics of genre. World Englishes 16(3): 359-371.

Bonini T (2015) The 'second age' of podcasting: Reframing podcasting as a new digital mass medium. Quaderns del CAC 41(18): 21-30.

Briones R (2012). Move analysis of philosophy research article introductions published in the University of Santo Tomas. Philippine ESL Journal 9: 56-75.

Caiazzo L (2014) Emerging conventions in the verbal component of the 'about' page of British university websites. In Evangelisti Allori P, Bateman J and Bhatia VK (eds) Evolution in Genre. Bern Switzerland: Peter Lang.

Carle AC, Jaffee D and Miller D (2009) Engaging college science students and changing academic achievement with technology: A quasi-experimental preliminary investigation. Computers and Education 52(2): 376-380. 
Carvalho AA, Aguilar C, Carvalho CJ and Cabecinhas R (2009) Influence of podcasts characteristics on higher students' acceptance. In Bonk C (ed) Proceedings of world conference on e-learning in corporate, government, healthcare, and higher education 2008. Chesapeake, VA: AACE, pp. 3625-3633.

Chambers J (2011) One Minute Tip Available at: http://www.oneminutetip.com/ (accessed 2 February 2017).

Drew C (2013) An ear for education: the sonic mode of address in education studies (review essay). The Australian Educational Researcher, 40(5), 649-657.

Drew C (2017) Edutaining audio: an exploration of education podcast design possibilities. Educational Media International. 54(1): 48 - 62. doi: 10.1080/09523987.2017.1324360

Edirisingha P, Hawkridge D and Fothergill J (2010) A renaissance of audio: Podcasting approaches for learning on campus and beyond. European Journal of Open, Distance and E-Learning 1.

Edirisingha P, Salmon G and Nie M (2008) Developing pedagogical podcasts. In: Salmon G and Edirisingha P (eds) Podcasting for Learning in Universities Berkshire, UK: Open University Press, pp. 153-168.

Egan K (2001). The cognitive tools of children's imagination. Paper presented at the meeting of the European Early Childhood Education Research Association. Alkmaar, The Netherlands.

Fernandez L (2007) I upload audio therefore I teach. The Chronicle of Higher Education 53(18): 27.

Fernandez V, Simo P and Sallan JM (2009). Podcasting: A new technological tool to facilitate good practice in higher education. Computers and Education 53(2): 385-392. DOI:10.1016/j.compedu.2009.02.014

Fernandez V, Sallan JM and Simo P (2015) Past, present, and future of podcasting in higher education. In Li M and Zhao Y (eds) Exploring Learning \& Teaching in Higher Education. Berlin: Springer, pp. 305-330. 
Fothergill J (2008) Podcasts and online learning. In Salmon G and Edirisingha P (eds) Podcasting for Learning in Universities. Berkshire, UK: Open University Press, pp. 80-91.

Guinda CS (2015) Genres on the move: Currency and erosion of the genre moves construct. Journal of English for Academic Purposes 19: 73-87.

Hew KF and Cheung WS (2013) Use of Web 2.0 technologies in K-12 and higher education: The search for evidence-based practice. Educational Research Review 9: 47-64.

Hew KF (2009) Use of audio podcast in K-12 and higher education: A review of research topics and methodologies. Educational Technology Research and Development 57(3): 333-357.

Jenkins H (2006) Convergence culture. New York: New York University Press.

Kemp PK, Myers CE, Campbell MR and Pratt AP (2010) Student perceptions and the effectiveness of podcasting in an Associate Degree Nursing program Teaching and Learning in Nursing 5(3): 111-114.

Kidd W (2011) Utilising podcasts for learning and teaching: A review and ways forward for e-learning cultures. Management in Education 26(2): 52-57.

Kim B and Reeves TC (2007) Reframing research on learning with technology: In search of the meaning of cognitive tools. Instructional Science 35(3): 207-256.

Larkin HE (2010) But they won't come to lectures. The impact of audio recorded lectures on student experience and attendance. Australasian Journal of Educational Technology 26(2): 238-249.

Lazzari M and Betella A (2007) Towards guidelines on educational podcasting quality. In Smith M and Salvendy G (eds) Human interface and the management of information. Lecture Notes in Computer Science. Heidelberg: Springer, pp. 404412.

Lee M and Tynan B (2008) Podcasts and distance learning. In Salmon G and Edirisingha P (eds) Podcasting for Learning in Universities. Berkshire, UK: Open University Press, pp, 92-102. 
Lindgren M (2016) Personal narrative journalism and podcasting. Radio Journal: International Studies in Broadcast \& Audio Media 14(1): 23-41. doi:10.1386/rjao.14.1.23_1.

Lüders M, Prøitz L and Rasmussen T (2010) Emerging personal media genres. New Media \& Society 12(6): 947-963.

Madsen V and Potts P (2010) Voice-cast: The distribution of the voice via podcasting. In N Neumark, R Gibson and $\mathrm{T}$ van Leeuwen (Eds) Voice: Vocal aesthetics in digital arts and media. Cambridge: MIT Press, pp. $33-60$.

McGarr O (2009) A review of podcasting in higher education: Its influence on the traditional lecture. Australasian Journal of Educational Technology 25(3): 309321.

Meserko V (2015) The pursuit of authenticity on Marc Maron's WTF podcast Continuum: Journal of Media \& Cultural Studies 29(6): 796-810.

Salvati A (2015) Podcasting the past: Hardcore History, fandom, and DIY histories. Journal of Radio \& Audio Media 22(2): 231-239.

Swales JM (1990) Genre analysis: English in academic and research settings. Cambridge University Press.

Tardy C and Swales J (2014) Genre analysis. In Schneider KP Barron A (eds) Pragmatics of discourse. de Gruyter Mouton: Berlin, pp. 165 - 187.

Tolson A (1991) Televised chat and the synthetic personality. In Scannell P (ed), Broadcast Talk. London: Sage Publications, pp. 178-200.

Wrather K (2016) Making 'maximum fun' for fans: Examining podcast listener participation online. The Radio Journal - International Studies in Broadcast \& Audio Media 14(1): 43-63. DOI: 10.1386/rjao.14.1.43_1 